\title{
Worthy Programme, Unworthy Implementation: A Case of Ghana's Livelihood Empowerment against Poverty
}

\author{
Desmond Tweneboah-Koduah \\ Department of Political Science, University of Ghana, Accra, Ghana. \\ Email:desmond670@yahoo.co.uk
}

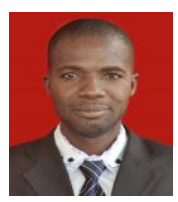

\begin{abstract}
Many well thought poverty reduction programmes implemented in Ghana have failed to deliver on their intended goals due to political interference. The main purpose of this study was to examine the extent to which the beneficiaries of Ghana's Livelihood Empowerment against Poverty have come from the ranks of the poor and the vulnerable. Thus how strictly the programme's eligibility criteria has been enforced at the implementation level. Concurrent Mixed Methods approach was employed to collect and analyse data from the field. Quantitative data was obtained from 360 beneficiaries of LEAP and 12 officials selected from government institutions and civil society organizations associated with LEAP implementation provided the qualitative data. The study area covers 8 selected Metropolitan/Municipal/District Assemblies from Greater Accra and the Northern region of Ghana. The findings indicated that the mandated eligibility criteria for the selection of the beneficiaries were observed more in breach than in compliance. The study also found that political clientelism has been a key feature of LEAP implementation, and that the provision of LEAP benefits has become contingent on the individuals' political support for the party of the ruling government. The study therefore recommends an active involvement of the media and civil society organisations in the implementation to enable them to expose most of the abuses carried out by politicians.
\end{abstract}

Keywords: Implementation, Political clientelism, Poverty reduction, Livelihood empowerment against poverty (LEAP).

JEL Classification: Code: I38: Welfare, Well being, and poverty: Government programmes: Provision \& effects of welfare programmes LEAP).

Citation | Desmond Tweneboah-Koduah (2020). Worthy Programme, Unworthy Implementation: A Case of Ghana's Livelihood Empowerment against Poverty. Asian Journal of Social Sciences and Management Studies, 7(3): 219-228.

History:

Received: 5 May 2020

Revised: 8 June 2020

Accepted: 3 July 2020

Licensed: This work is licensed under a Creative Commons

Attribution 3.0 License (oc)

Publisher: Asian Online Journal Publishing Group
Funding: This study received no specific financial support.

Competing Interests: The author declares that there are no conflicts of interests regarding the publication of this paper.

Transparency: The author confirms that the manuscript is an honest, accurate, and transparent account of the study was reported; that no vital features of the study have been omitted; and that any discrepancies from the study as planned have been explained.

Ethical: This study follows all ethical practices during writing.

\section{Contents}

1. Introduction

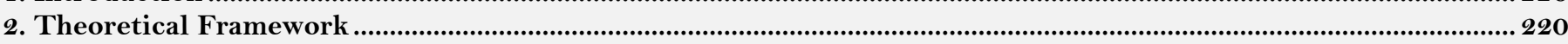

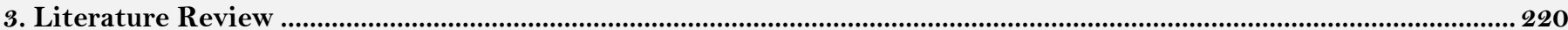

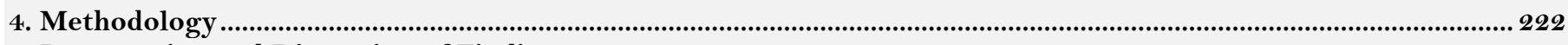

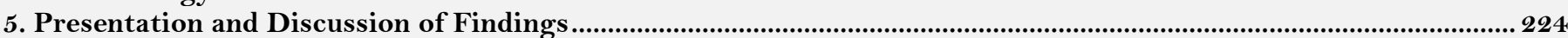

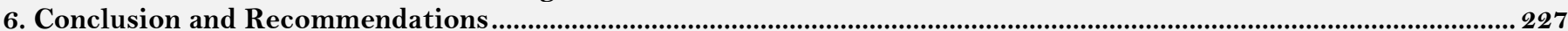

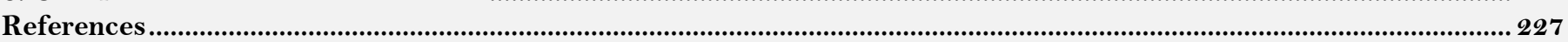




\section{Contribution of this paper to the literature :}

The previous studies have acknowledged the presence of clientelism in Ghanaian politics; this study has highlighted the nature, the extent and effects of political clientelism on Ghana's LEAP implementation. It has uncovered active involvement of political parties in the selection process. The findings from the study have also confirmed the findings of other studies which give validity, and further provides a reliable basis for developing policy measures.

\section{Introduction}

Ghana has been recognised as the beacon of democracy in Africa. However, the trust that the country can represent Africa's best chance to grow out of widespread poverty appears to have become far-fetched (Devereux \& White, 2010). Since independence in 1957, Ghana has implemented various strategies aimed at poverty reduction to improve the living condition of the poor and vulnerable, however, the expected target is yet to be achieved. As a result, the search for the appropriate poverty reduction strategy is still on with knowledge transfer from previous strategies and programmes as a guide.

On return to constitutional rule in 1992, the 1992 Republican Constitution in Article 36(1) enjoins the state to take all necessary measures to provide adequate means of livelihood to all citizens and public assistance to the needy (Republic of Ghana, 1992). To achieve these ends, several policies and programmes have been implemented since 1992. These include Ghana Vision 2020 (The First Step 1996-2000), Ghana Poverty Reduction Strategy 2003-2005 (GPRS I), Growth and Poverty Reduction Strategy 2006-2009 (GPRS II) among others (National Development Planning Commission. 2013). Although the implementation of these programmes yielded some positive outcomes, there were considerable number of challenges that affected their level of success. Key among these challenges included: unrealistic implementation strategies, inadequate financing, patron-client relations and patronage (Ayee, 2007) the problem of misalignment of resource allocation and poor donor support (National Development Planning Commission. 2015).

In the midst of the preponderance of poverty, the New Patriotic Party (NPP) government led by J.A. Kuffour introduced the Livelihood Empowerment against Poverty (LEAP) programme in 2008 as a strategy to address extreme poverty. As a measure to limit the leakage of benefits beyond the targeted groups, the LEAP policy document adequately provided for unambiguous criteria for the selection of eligible beneficiaries. The selection criteria among other things included: extremely poor household, Orphaned and Vulnerable Children (OVC), persons with severe disability and without any productive capacity, the elderly persons who are 65 years and above, and the very poor pregnant and infants below the age of one year (Debrah, 2013a). The introduction of the LEAP programme engendered an optimism among Ghanaians not only because the programme was well-designed but also with the expectation that the political class had the benefit of learning from the past mistakes such as the preferential inclusion of some groups and the exclusion of others. Under a typical democratic dispensation like Ghana, the use of meritocracy as a criterion for accessing state-funded poverty alleviation programme should be the norm, not an exception. While some critics of LEAP have made claims about fraudulent participation, pointing to cases of registered beneficiaries who do not appear to satisfy the eligibility criteria (Agbaam \& Dinbabo, 2014) others have argued that the programme has been successful in reducing poverty (Handa et al., 2013). Though substantial research has been done on the impact of LEAP on Ghana's poverty reduction effort, very little work has been done on how the employing programme's eligibility criteria has been enforced. This article sought to fill the vacuum by using mixed method approach to provide empirical evidence to illustrate how a worthy programme like LEAP could be made to become unworthy in its delivery. In particular, the study sought to examine the role played by political clientelism in the implementation process. In this regard, the research questions which guided this study were as follows: (a) what have been the processes involved in the selection of LEAP beneficiaries in practice? (b) to what extent has LEAP programme been characterised by clientelistic politics in its implementation? The article is presented in six sections. After the above introductory section, the section two is devoted to the theoretical framework. Section three, reviews the relevant literature to the study. The fourth section deals with the methodology of the study. The fifth section presents and discusses the findings of the study, section six ends with the conclusion and recommendations.

\section{Theoretical Framework}

This study was located within the Rational Choice Theory (RCT) framework propounded by James Buchanan (Anderson, 2011). As a theoretical tool, it was used to evaluate the actions of both the public officials and beneficiaries involved in the implementation of LEAP. Rational Choice Theory explains what motivates the political actors to do what they do. Besides, the theory has been used extensively by researchers over the years to provide useful insight into the actions of politicians, voters and lobbyists (ibid). The adopted framework therefore provided a broad theoretical lens for a comprehensive understanding as to why a satisfactorily well-crafted LEAP implementation guidelines would be sacrificed on the altar of clientelistic politics. In the words of Stokes (2009), political clientelism is the proffering of material goods in return for electoral support, where the criterion of distribution that the patron uses is simply: did you (will you) support me?' The framework therefore becomes relevant on the grounds that the extent of clientelistic politics in the LEAP implementation has a direct consequence on the rate at which the goals of the programme could be translated into reality.

\section{Literature Review}

A number of studies have gone into public policy implementation, poverty reduction strategies and social protection policies across the globe and Ghana in particular. To put this article into proper context, the brief review of the literature focused on policy implementation in general, poverty reduction in Ghana and studies on Ghana's LEAP. 


\subsection{Studies on Public Policy Implementation}

Governments all over the world use one public policy or the other as a tool to solve problems that confront their people. There appears to be a general agreement in the implementation literature that policy goals can best be translated into reality through effective implementation. Implementation is the process of fulfilling a given task to address a specific problem. For Ibrahim, Yulianto, Zuchri, and Hiola (2017) if a public policy is not properly implemented, it can best be described as a good plan that is neatly stored in archive. It can therefore be argued that the act of implementing a poverty reduction programme is ostensibly meant to be a matter of carrying out that which has been decided upon already (Grindle \& Thomas, 1991). On the contrary, this exercise which Tezera (2019) describes as the most critical aspect of the policy making process continues to be a challenging puzzle for most governments in developing democracies.

Scholars have alluded to implementation hiccups as the reasons for the failure of most public policies. For instance, Iyanda and Bello (2016) hold the view that the failure of the governments to realise public policy goals have turned implementation to be the graveyard of the policy process. Ayee (1994) on his part has observed that many public policies made in developing countries are mostly not implemented at all, and in few situations where implementation is carried out, the process often deviates from the intentions of the policy-makers.(Obadan, 2001) in assessing why various poverty reduction programmes have failed in Nigeria came to a conclusion that lack of accountability and transparency in programme implementation have turned the programmes to become conduit pipes for draining national resources. Echoing similar view, Makinde (2005) enumerated politicization, corruption, lack of continuity in government policies and inadequate material resources among others as the key factors responsible for the implementation gaps in developing nations.

On the conditions for successful policy implementation, Frank, Gerald, and Mara (2007) enumerated clarity of policy objectives, strong commitment of the implementing official toward the policy goal, adequate structuring of the implementation process, significant support from both interest groups and the political class, and absence of detrimental changes in the existing socioeconomic framework as factors that must be at play for implementation success. Flowing from the above narratives, it is safe to state that in as much as policy implementation may be a challenging task, the implementation literature have provided crucial guidelines and clear action plan for governments to follow in order to translate the goals of public policies into reality.

\subsection{Poverty Reduction in Ghana}

Poverty reduction activity is not new in Ghana, and several studies have reported on the country's efforts so far. For the purpose of this study a few would be reviewed. Although a lot of the studies have espoused that the attempts by governments to tackle poverty has been on-going since independence in 1957, they have however conceded that the effort increased quite dramatically after the promulgation of the 1992 Constitution. For instance, Gagakuma (1998) and Leitre et al. (2000) have intimated that Ghana's Vision 2020 framework aimed at consolidating the gains made over the past decades, and to lay strong foundation for accelerated growth for the future. However, Armah (2008) and The Institute of Economic Affairs (2002) contended that while the policy framework made considerable progress in restoring macroeconomic stability, it could not achieve its intended objectives due to inadequate funding. The implementation of Ghana's Vision 2020 got truncated after the change in government in 2000, and the new government introduced Ghana Poverty Reduction Strategy (GPRS 1) as a tool to fight poverty. It is important to note that the GPRS 1 was not only introduced to address the challenges of the Vision 2020 framework but also initiated as a condition for development assistance under the IMF and World Bank supported Heavily Indebted Poor Countries (HIPC) debt relieve programme in 2002 (Aryeetey \& Kanbur, 2006; National Development Planning Commission, 2010). For Aryeetey and Baah-Boateng (2007) the GPRS 1 failed to make the anticipated reduction in poverty due to its apparent over-concentration on achieving macroeconomic stability to the neglect of structural problems. In discussing the weaknesses of the GPRS 1 Amoako-Tuffour (2008) added that poor programme design, weak institutional coordination and poor targeting contributed significantly to the inability of the framework to deliver on its poverty reduction goal. To consolidate the gains made through the implementation of GPRS I, another medium- term development policy framework namely Growth and Poverty Reduction Strategy 2006-2009 (GPRS II) was implemented. The available evidence indicates that the mainstreaming of the Millennium Development Goals (MDGs) into both the GPRS I and GPRS II helped Ghana to achieve the MDG 1, thus the target of halving the proportion of people living in extreme poverty in 2006 ahead of time (National Development Planning Commission. 2015). Despite the impressive growth performance Ghana achieved under GPRS I \&II, a review by Carr (2008) revealed that the GPRS II in particular did not live up to the ideals for which it was created. He argued that the document which sought to address poverty from all sectors of the economy failed to develop an integrated implementation plan to ensure a coordinated action. The latest major poverty reduction strategy documents Ghana has implemented include the Ghana Shared Growth and Development Agenda (GSGDA I), 2010-2013 and the Ghana Shared Growth and Development Agenda (GSGDA II), 2014-2017). The overall goal of these two poverty reduction strategies was to accelerate the growth of Ghanaian economy with the view to ensure sustainable poverty reduction (National Development Planning Commission. 2013). After years of implementing these growth driven programmes, the reported gains from the economic growth did not have any significant impact on the country's incidence of poverty (Cook, Hague, \& McKay, 2016). Providing explanation as to why Ghana has experimented with several poverty reduction strategies yet poverty remained endemic (Debrah, 2013; Ninsin, 2016) and Ayee (2007) have all intimated that the partisan nature of politics played in the country makes it difficult for the selection process of the programmes to operate on the merit principle. They have argued that factors such as political affiliation and ethnic considerations have always been given greater weight. Allah-Mensah (2006) on her part postulated that whenever programmes instituted to reduce poverty are not beneficiary-centred, such programmes cannot make any significant impact on the poor. It can also be gleaned from the above review that Ghana's poverty effort has been driven by the assumption that economic growth would lead to automatic reduction in poverty everywhere. However, the evidence from the literature has proven that such belief has been less likely than many had anticipated. 


\subsection{Implementation of Ghana's Livelihood Empowerment against Poverty}

Since the inception of the implementation of the LEAP programme, a considerable amount of ink has been poured on the subject matter. While scholars such as Park, Handa, Osei, and Osei-Akoto (2012) have highlighted the unique nature of LEAP by pointing out how the beneficiaries are made to benefit from free health insurance scheme in addition to the cash transfers, others have focused on the impact it has made on poverty reduction in Ghana. For instance, Korboe, Dogbe, and Marshall (2011); Handa et al. (2013); Thome, Taylor, Davis, and Darko (2013); Groot et al. (2015) and Davis et al. (2014) have all come to a unanimous conclusion that the programme has largely impacted positively on the beneficiary households particularly in the areas such as the well-being of the people, improvement in the beneficiary's children education in terms of school enrolment, grade repetition, absenteeism and frequency of utilization of healthcare facilities among others.

Other studies conducted by Agbaam and Dinbabo (2014) and Abbey, Odonkor, and Boateng (2014) highlighted the key challenges facing the programme which include irregular payment, weak linkage of the programme to other pro-poor interventions, inadequate staff with limited operational capacity and low coverage of poor family. Similarly, Jaha and Sika-Bright (2015) identified perceived political manipulations and political interferences as other major challenges confronting the smooth implementation of the programme. According to the World Bank (2011), the LEAP like any other social intervention programmes has always been bedeviled with the issue of improper targeting and that various attempts have been made to improve the targeting procedures. Debrah (2013b) has indicated that the success of LEAP is dependent on the implementers' ability to get the targeting right. Martei (2015) supported (Debrah, 2013) and further added that the absence of definite indicators for measuring success in the LEAP implementation guidelines has led to a situation where the key measure of progress is a ballooning number of the beneficiaries. In their study to assess how the LEAP programme has empowered the beneficiaries to manage risk and re-engage with informal social networks, Daidone et al. (2015) found that the inability of the government to disburse the benefits promptly has negatively affected the realization of LEAP stated objectives. As part of the eligibility criteria, LEAP has a number of conditionalities which include children enrolment and retention in schools, registration of births, elimination of child trafficking and children engaged in worst form of child labour among others (Gbedemah, Jones, \& Pereznieto, 2010). Meanwhile a study by Park et al. (2012), on LEAP beneficiaries' adherence to these conditionalities revealed as many as 83 percent of the beneficiary households did not comply with any conditionality before they received their cash payments. This implies that even the conditionalities which were instituted to ensure that the beneficiary households were held in constant checks suffered weak enforcement.

In short, the review of the relevant literature have focused on public policy implementation, poverty reduction strategies in Ghana and studies on the implementation of LEAP. Whereas these earlier studies are important because they have highlighted important aspects of the implementation of poverty reduction programmes such LEAP, little work has been done to establish whether the beneficiaries of LEAP solely come from the ranks of the poor and the vulnerable This study is designed not only to fill the lacuna in the literature but also to examine how LEAP's eligibility criteria has been enforced, and to indicate an important direction for future research.

\section{Methodology \\ 4.1. Research Design}

The study employed Concurrent Mixed Methods Design. The method involves the collection of both quantitative data and qualitative data simultaneously. It is also underpinned by the pragmatist principle which argues that looking at a phenomenon from different perspectives provide richer and comprehensive understanding than by looking at it from a single perspective (Neuman, 2011). The data collected from both the quantitative and qualitative sources were therefore compared to determine if there were corroborations or differences in the findings. More importantly, the selection was influenced by the complex task of providing an explanation to the question of why a well-designed programme could fail to achieve its intended goals when implementation guidelines were clearly provided.

\subsection{Purpose of Research Type}

The study was primarily an explanatory research which sought to explain the behaviour of political actors in the implementation of LEAP programme. It was to support or refute the predictions or principles of Rational Choice Theory through the utilization of multiple sources of evidence. As explained by Neuman (2011) explanatory researcher is usually interested in learning why things or events occur, and link the issues to the general principles of a theory. In this particular case, the study did not only seek to explain the actions of both the politicians and the beneficiaries associated with the process of LEAP implementation, but also took interest in understanding why poverty reduction programmes fail, through the utilization of the key assumptions of rational choice theory.

\subsection{Method of Study \\ 4:3.1. Sources of Data}

The study was based on both primary and secondary sources of data. The information which was collected from respondents of the study constituted the primary data. On the other hand, all the information gathered from the previously documented materials on the topic of study formed secondary data (Dawson, 2006). These secondary sources of data provided a useful background understanding of the subject matter and also provided insight into the analysis and interpretation of the findings obtained from the field. Within the context of this study, the data from the primary source was used to validate the findings obtained from the secondary sources.

\subsection{Selection of Study Areas and Respondents \\ 4.4.1. Study Areas Selection Procedure}

The beneficiaries of the LEAP programme are geographically spread across Ghana. Thus, they are found in all the then ten administrative regions and the then 216 Metropolitan, Municipal and District Assemblies (MMDAs) 
of the country. Within the regions and the MMDAs, the number of beneficiaries differs from one area to another. Besides, 56 percent of the beneficiaries were women while 44 percent were men (Ministry of Gender Children and Social Protection, 2017). In order to overcome some of the disadvantages inherent in both probability and purposive samples, a mixture of sampling techniques has been used in the study. The study therefore employed cluster probability sampling method/multistage random area sampling (Ethridge, 1994). With this technique, the entire country was divided into two major clusters, namely the northern zone and the southern zone. The northern zone included the Northern, Upper East, Upper West, Brong Ahafo and Ashanti Regions. While the southern zone consisted of Greater Accra, Eastern, Volta, Western and Central regions. From the two clusters, the Northern and the Greater Accra regions were purposively selected to represent the north and the south divide respectively. Within these two regions, four MMDAs were also purposively chosen from each region using the incidence of poverty and MMDA's (constituency's) loyalty to either New Patriotic Party (NPP) or National Democratic Congress (NDC), the two major political parties as criteria. As intimated by Silverman (2006) purposive sampling technique becomes more appropriate when an area exhibits some features of interest relevant to the phenomenon under study. The eight MMDAs which fully fulfilled the two criteria included Shai-Osudoku and La Dade Kotopon representing the poorest and the least poor MMDAs in Greater Accra respectively (Ghana Statistical Service. 2015) the Ga East and Ga West Municipalities represented the electoral strongholds for the NPP and NDC political parties respectively (Electoral Commission of Ghana, 2016). The MMDAs selected from the Northern Region included East Gonja and Tamale Metropolis being the poorest and least poor MMDAs respectively in the region (Ghana Statistical Service, 2015) the Yendi and the Kumbungu districts on the other hand served as the electoral strongholds for the NPP and NDC political parties respectively in the region (Electoral Commission of Ghana, 2016).

\subsection{Justification for the Study Areas}

Generally, the purpose of choosing the above two regions among others was to make sure that the findings from the study reasonably reflect geographical differences in the LEAP implementation process. Besides, Greater Accra and Northern regions possess some unique features worth investigating. For instance, available statistics indicated that Greater Accra has experienced the highest reduction in poverty level since the beginning of LEAP and also it holds the least number of poor people in Ghana. Thus, 241,166 peoples (Cook et al., 2016)(Ghana Statistical Service, 2015). On the other hand, the Northern region has experienced the least reduction in the level of poverty since 2008, it holds the highest number of poor people in Ghana (1.3 million people) (Cook et al., 2016)(Ghana Statistical Service, 2015). The Northern region also hosts the East Gonja which is the poorest in all the then 216 MMDAs in Ghana and it is a rural district making it an interesting case for investigation (Ghana Statistical Service, 2014). Again, both Greater Accra and the Northern regions have the least and highest number of LEAP beneficiaries respectively in the country and they provide unique cases for comparison in terms of selection of the beneficiaries (Ministry of Gender, Children and Social Protection, 2017). Additionally, the World Bank (2011) has stressed that Ghana's poverty reduction success story has always been the success story of its southern sector. Therefore, until efforts are made to do away with the historical North-South divide in the standard of living, poverty would continue to persist in the country. On the basis of this concern, the study sought to investigate how the LEAP has been implemented within this historical North and South divide over the years as well. The Table 1 below indicates the four selected MMDAs from the two regions based on their levels of poverty as presented in the 2015 Ghana Poverty Mapping Report by Ghana Statistical Service. See the table for details:

Table-1. Selected Regions and MMDA's for the study based on poverty level

\begin{tabular}{c|c|c}
\hline Selected Regions & Poorest District Selected from the Region. & Least Poor District in the Region \\
\hline Greater Accra & Shai Osu Doku & La Dade Kotopon \\
\hline Northern & East Gonja & Tamale Metropolis \\
\hline
\end{tabular}

Again, some politicians usually adopt different strategies to ensure that they are able to convert the distribution of poverty reduction benefits into political support and loyalty. Magaloni (2006) suggests that the politicians can use the distribution of the material benefits in various ways possible. They can use such poverty reduction benefits to consolidate political support or reward supporters in their strongholds. In addition, the material benefits can be used in the area considered to be the stronghold of their rival parties in order to dilute their opponents support. On the basis of this information, other two MMDA's each were purposively selected from the two regions to investigate for evidence of political manipulations in LEAP implementation. Thus Ga East and Yendi MMDAs, which have proved to be electoral strongholds for NPP and Ga West and Kumbungu district too have proved to be electoral strongholds for NDC parties respectively Electoral Commission of Ghana (2017).

\subsection{Selection of Survey Respondents}

The total population of the beneficiary households in these eight selected MMDAs as at July 2018, stood at 7162 , with the current gender ratio composition of 56:44 for females and males respectively (Ministry of Gender, Children and Social Protection, 2017). To achieve meaningful representative sample for such a study, the ideal sampling approach for the survey should have been to employ a simple random sample of the entire beneficiary households throughout the selected MMDA's. However, this strategy was practically impossible for the study due to its implications on the travel cost and time. For this reason, a list made up of 7162 LEAP beneficiary households was obtained from all the eight District Social Welfare Officers from the selected MMDAs. This compiled list served as the sample frame for the survey. For the study being a mixed method in nature, a sample size of five (5) percent of the study population was representative (Webb, 1989). The five percent of 7162 households constituted 360 beneficiary households. The study therefore settled on 360 beneficiary households across the selected MMDAs for the survey. A quota of five (5) percent was selected from the total number of beneficiaries in each MMDA with a gender ratio of 56:44. The sampling objective was to ensure that the number of respondents randomly selected from each MMDA was proportional to the number of beneficiary households in the area. The next stage of the 
sampling process involved the random selection of a LEAP beneficiary from the sampled households from each selected MMDA to represent their respective households. Generally, the mathematical formulae for the selection of respondents from each district was: $\mathrm{N}=\mathrm{n} \times 5 \% \times 360(56: 44$ gender ratio). Where $\mathrm{N}$ is the number of respondents in an MMDA and " $n$ " is the total number of beneficiary households in an_MMDA.

\subsection{Selection of Interviewees for the Qualitative Study}

The participants for the qualitative research came from diverse segments of the population from both state and non-state actors. They were purposively selected because of their involvement and deep knowledge in poverty reduction activities and LEAP implementation in Ghana. They included the LEAP programme Manager, eight (8) MMDA Social Welfare Officers representing the eight (8) selected MMDAs, one (1) Official each from Ghana Centre for Democratic Development (CDD), IMANI Center for Policy and Education-Ghana and Institute for Democratic Governance (IDEG) representing the Civil Society Organizations involved in poverty reduction activities and LEAP in Ghana. In all 12 key respondents were purposively selected and interviewed.

\subsection{Data Collection Instruments and Procedure}

For a better understanding of the problem under investigation, various data collection instruments were used to collect both the quantitative and qualitative data. With regard to the survey data, first the consent of all the respondents of the survey were sought before the questionnaires were administered. The data were gathered through an interviewer-administered questionnaires which contained a combination of open-and closed-ended questions. The reason for interviewer-administered questionnaires was that the educational levels of most of the LEAP beneficiaries who were the key respondents of the study were low. Where the respondents did not understand English or the language used by the researcher, the services of trained local language interpreters were hired for them to translate the questions for such respondents. This was to ensure that the respondents understood the questions adequately before they responded to the questions. On the other hand, the interviews with the 12 officials were all scheduled days ahead before they were conducted. Permission was sought from each official before the interviews could be recorded. The qualitative data were collected through semi-structured face-to face interviews with an interview guide to provide direction.

\subsection{Data Analysis Procedure}

The analysis of the data simply focused on the search for patterns in the data in order to interpret the identified patterns within the context of rational choice theory. This involved critical examination of the raw data, sorting, categorization, evaluation and the synthetization among others (Neuman, 2011). The exercise also to a large extent helped in explaining how the raw data relate to the research questions for the study. The interpretation of the data from both the quantitative and qualitative data sources were done side-by-side to determine whether there was a convergence or differences in the findings from each method of study (Morgan, 1998). The quantitative data which was gathered from the survey was first coded and subsequently entered into IBM SPSS version 20 for descriptive and inferential analysis. Pearson Chi-Square test was carried out to establish whether there has been a relationship between political clientelism and areas where the beneficiaries of LEAP were selected from. Thus Person ChiSquare is a statistical tool used to test whether there exist any relationship between two categorical variables. Specifically, in this study the test was interested in finding out whether the beneficiaries' electoral constituency (MMDAs) be it NPP stronghold, NDC stronghold or politically neutral constituency has any significant relationship with other interested variables such as beneficiaries association with the two major political parties. In the analysis for the Chi-Square, all the tests were performed at $5 \%$ level of significance. Thus in all the analysis an alpha of 0.05 was used as the cut-off for the level of significance. For the qualitative data, the analyses were done thematically using Nvivo 12 (Pro Version). The thematic analysis began with the used of Microsoft Word Office to transcribe the audio-recordings from the interviews into texts. The transcribed data was then imported into the Nvivo software for further analysis. With the help of the software, the data were coded for the process of categorization and sub-categorizations to be carried out.

\section{Presentation and Discussion of Findings}

\subsection{Assessment of the Processes Involve in the Selection of LEAP Beneficiaries}

The issue of weak targeting associated with the LEAP programme as a result of political interference has been a source of major concern to many stakeholders (Jaha \& Sika-Bright, 2015). The study sought to establish the views of the social welfare officers who have been directly involved in the LEAP implementation whether the selection process is rule-based. All the nine officials who were interviewed emphatically stated that the selection of the beneficiaries is based strictly on eligibility criteria, which cannot be compromised. They were then asked to describe the stages involve in the selection process. They explained that it is the selection of the communities which has seen major changes over the years. The following sums-up how they explained the selection process:

"The Ministry of Gender, Children and Social Protection has over the years used two methods in the selection, and the difference between the two is who selects the community. Previously the communities in the MMDAs were selected using the Ghana Poverty Mapping Reports by the Ghana Statistical Service while with the current process the respective District's LEAP Implementation Committees (DLICs) select the community. After the community selection, the District Social Welfare Officer and his outfit go to the community to sensitize the people in the community on all what LEAP is about. The officials from a Non-Government Organization by name ESOKO, with the support of a community focal person visits the selected communities to collect data on the prospective beneficiaries and the data is sent to the LEAP Secretariat to be processed. The LEAP Secretariat receives the data directly from ESOKO for the assessment of poverty status of the families/households and the preparation of the list of selected beneficiaries follows. The prepared list of the selected beneficiaries is therefore sent to the MMDAs for us to invite and prepare them for payment to commence" 


\subsection{Extent of Political Interference in the Selection Process}

On paper, there is a clearly stated eligibility criteria for the selection of LEAP beneficiaries. The study sought to gauge the views of the respondents on whether the process is interfered by politicians or other influential people. In stark contrast to their previous responses that the selection is rule-based, eight out of the nine Social Welfare Officers who are directly in-charge of the programme at the MMDAs admitted that political interference is a regular feature in the selection process. The following statement captures the sentiments expressed by all the officials interviewed:

"As for political manipulations and interference they are common, even in 2016 when we were doing LEAP 1000 enrolment, a party chairman and the women organizer insisted that we have to finish registering their prepared list before we can register "outsiders" which I obliged. Additionally between October and November in the same year, there was an emergency expansion which enrolled 2585 people unto the programme in this district before the election. Meanwhile the entire existing beneficiaries were 1,095" (Officer D3).

Findings from the survey corroborated the high political interference in the selection process which was established in the qualitative study. For instance, more than half (53\%) of the respondents admitted that they were selected for the LEAP through the assistance of their Assembly member. The most revealing part of this result is that during the data collection at the field, it was observed that almost all the assembly members who were playing the role as LEAP community focal persons were bold to indicate their political party affiliations which gives an indication that there has been a partisan element in the selection process. Again, as shown in Table 2 below, whereas the majority of respondents in NPP strongholds benefited from LEAP through the assistance of government officials (66\%), majority of those in NDC strongholds (73\%) and MMDAs considered to be politically neutral (55\%) benefited from LEAP through the assistance of their assembly member. These data imply that the selection process is influenced by other influential people in spite of the clear-cut eligibility criteria.

Table-2. Source of assistance towards LEAP selection.

\begin{tabular}{|c|c|c|c|c|c|c|}
\hline \multirow[b]{2}{*}{ Source of assistance for selection } & \multicolumn{4}{|c|}{ Beneficiaries' Electoral Constituency } & \multirow{2}{*}{$x^{2}$} & \multirow{2}{*}{$\mathbf{P}$} \\
\hline & NPP & NDC & Neutral & All & & \\
\hline A friend & $2 \%$ & $1 \%$ & $1 \%$ & $1 . \%$ & \multirow{7}{*}{48.53} & \multirow{7}{*}{$0.00^{*}$} \\
\hline Party member & $2 \%$ & $5 . \%$ & $7 . \%$ & $6 \%$ & & \\
\hline Government Official & $66 . \%$ & $14 \%$ & $33 . \%$ & $35 . \%$ & & \\
\hline Church/Mosque Member & $2 \%$ & $3 \%$ & $1 \%$ & $2 \%$ & & \\
\hline Assemblyman/woman & $25 \%$ & $73 \%$ & $55 . \%$ & $53 . \%$ & & \\
\hline Other & $3 \%$ & $4 \%$ & $3 \%$ & $3 \%$ & & \\
\hline Total & 100 & 100 & 100 & 100 & & \\
\hline
\end{tabular}

From the study, it was found that on paper the selection of the beneficiaries is based strictly on clearly stated eligibility criteria. However, in practice, widespread political interference has rendered the strict application of the stated eligibility criteria ineffective. The above findings suggest that even though there are unambiguous guidelines which regulate the selection of LEAP beneficiary communities and individuals, politicians are able to circumvent the rules to enable them to influence the selection process. These findings validate the assumption of rational choice theory which contends that the actions of politicians are guided by the pursuit of their own selfinterest rather than by an altruistic commitment. It explains that politicians in their desperate quest to pursue their self-interest can easily manipulate laid down rules in order to achieve their preferred outcome (Anderson, 2011). In the case of LEAP, attempts by politicians at both national and local levels to interfere with the process of selecting the beneficiaries is inconsistent with the standard operating procedures stated in the LEAP policy document (Ekobor-Ackah, Darko-Osei, \& Osei-Akoto, 2014). Again, within the existing literature, the findings corroborate studies by Jaha and Sika-Bright (2015), and Abane (2017). This finding also reinforces (Whitfield, 2011) that many poverty alleviation initiatives in Ghana have failed to achieve their intended objectives because of excessive political interference in the targeting process. Clearly, this attempt by the political elite to side-step the eligibility criteria in the selection of LEAP beneficiaries as the study reveals points to the fact that the beneficiaries of the programme do not solely come from the ranks of the poor and the vulnerable.

\subsection{Political Clientelism as a Feature of LEAP Implementation}

Suspicion of political clientelism being an integral part of LEAP implementation is rife in Ghana and the study sought to investigate. In this regard, both the District Social Welfare Officers and officials from Civil Society Organizations operating in the study areas were interviewed. The study revealed that politicians have always used the LEAP as a political tool to reward their party supporters. They do this by first influencing the selection of the communities where they know their supporters are concentrated before they subsequently influence the selection of individual beneficiaries. The political parties operate through the MMDAs which are headed by Chief Executives who are political appointees and represent the interest of the appointing authorities. This view ran through all the responses from almost all the District Social Welfare Officer. According to one of the Officers labelled officer D6;

"On paper it does not serve any political interest because the objective of the programme is to help alleviate poverty. However, on the ground the politicians have always used it as a political tool to reward their supports. If any of us as professionals make any attempt to resist the politicians, you are likely to be transferred and wherever you are sent to, you are going to work under another District Chief Executive who would have already been provided with information about you before you get there. As you may be aware they have a platform that they discuss issues about the happenings in their districts." (Officer D6). Similar sentiments were expressed by all the officials from the Civil Society Organizations who were interviewed. For example, lamenting about this situation based on personal observation, an officer from the CSO's has this to say:

"I do have a serious problem with the selection of the communities to benefit from the programme, I see it to be discriminatory and politically motivated. From my own hometown in the Ahanta District in the Western Region, two 
communities with equal level of poverty, and because one community was a stronghold of a party in government it was quickly selected for LEAP, and the one perceived to be for the opposition party was ignored and as soon as the opposition won power, the other community which happened to be her stronghold benefited. The influence of the politicians on the selection process is widespread"

The results from the survey also revealed that three in five (59\%) respondents claimed that political party leaders at the MMDAs influence the selection of LEAP beneficiaries, about $22 \%$ of them disagreed. The rest $(19 \%)$ had no opinion about the influence of politicians in the selection process. The results from the Chi-Square test also revealed a strong relation between the influence of political party officials and selection of the beneficiaries from all the electoral constituencies $\left(x^{2}=23.02, \mathrm{p}<0.05\right)$. Also as shown in Table 3 below, though majority of respondents in NPP strongholds, NDC strongholds and MMDAs considered to be politically neutral were all of the opinion that politicians influence the selection of LEAP beneficiaries, the percentage of respondents who hold this view in NDC strongholds $(76 \%)$ is significantly higher than those in NPP strongholds (50\%) and MMDAs considered to be politically neutral $(56 \%)$.

Table-3. Do political party leaders influence selection of LEAP beneficiaries?

\begin{tabular}{|c|c|c|c|c|c|c|}
\hline \multirow[b]{2}{*}{ Influence from party officials } & \multicolumn{4}{|c|}{ Beneficiaries' Electoral Constituency } & \multirow{2}{*}{$x^{2}$} & \multirow{2}{*}{$\mathbf{p}$} \\
\hline & NPP & NDC & Neutral & All & & \\
\hline Yes & $50 \%$ & $76 \%$ & $56 \%$ & $59 \%$ & \multirow{4}{*}{23.02} & \multirow{4}{*}{$0.00 *$} \\
\hline No & $38 \%$ & $7 \%$ & $22 \%$ & $22 \%$ & & \\
\hline Don't know & $12 \%$ & $17 \%$ & $22 \%$ & $19 \%$ & & \\
\hline Total & 100 & 100 & 100 & 100 & & \\
\hline
\end{tabular}

Note: $*$ is significant at $\mathrm{p}<0.05$

\subsubsection{Regime that Selected Respondents to Benefit from LEAP}

Respondents were asked to indicate the regime within which they were selected. As high as forty eight percent $(48 \%)$ of the respondents indicated that they started benefiting from LEAP during the Mahama's regime (NDC, 2012-2016). Two in five (38\%) respondents cited Mills' regime (NDC, 2009-2012). Another 13\% of the beneficiaries mentioned Kuffour's regime (NPP, 2008-2009) and those selected under Akuffo Addo's regime formed 1\% (NPP, $2017+)$. Significantly, all the respondents $(100 \%)$ in the NDC strongholds benefited from LEAP during Mills' or Mahama's regime (NDC Regimes). The majority of respondents in the NPP strongholds benefited from LEAP during Kuffour's regime (38\%) (2008). However, no beneficiary was selected from the NDC stronghold which raises a question about how fair the selection process has been. Also, majority (58\%) of the respondents in the MMDAs considered to be politically neutral started benefiting from the LEAP during Mahama's regime. The outcome of the Chi-Square test indicates that there is a significant relationship between where the beneficiaries got their selection and the regime which selected them. These findings are interesting not only for the pattern they revealed with regard to how the regimes did their selection but also clear to indicate that selection for the LEAP beneficiaries is characterized by partisan considerations. See Table 4 for details.

Table-4. Regime under which respondents benefitted from Leap.

\begin{tabular}{|c|c|c|c|c|c|c|}
\hline \multirow[b]{2}{*}{ Regime of selection } & \multicolumn{4}{|c|}{ Beneficiaries' Electoral Constituency } & \multirow{2}{*}{$x^{2}$} & \multirow[b]{2}{*}{$\mathbf{p}$} \\
\hline & NPP & NDC & Neutral & All & & \\
\hline Kuffour & $38 \%$ & $0.0 \%$ & $9 \%$ & $13 \%$ & \multirow{5}{*}{77.41} & \multirow{5}{*}{$0.00^{*}$} \\
\hline Mills & $35 \%$ & $63 \%$ & $32 \%$ & $38 \%$ & & \\
\hline Mahama & $27 \%$ & $37 \%$ & $58 \%$ & $48 \%$ & & \\
\hline Akufo-Addo & $0.0 \%$ & $0.0 \%$ & $1 \%$ & $1 \%$ & & \\
\hline Total & 100 & 100 & 100 & 100 & & \\
\hline
\end{tabular}

Note: * is significant at $\mathrm{p}<0.05$.

\subsubsection{Respondents and Political Parties they Follow Most in the Media}

A follow-up question was asked to find out from the beneficiaries the political parties in Ghana they follow their activities most in the media. Judging from the responses to this question - see Table 5 , it is clear that majority of them are sympathizers of one or the other major political parties and follow their activities in the media. For example, fifty-nine percent (59\%) of the respondents indicated that they follow NDC activities through the media very often. Another $35 \%$ of them cited NPP activities whereas the rest (6\%) mentioned the minor political parties. Also, whereas majority of the respondents in NDC strongholds $(75 \%)$ follow NDC activities through the news, a significant portion of those in NPP strongholds (59\%) follow NPP activities most often in the news. The results from the Chi-Square test also support the assertion that there is a significant relationship between their electoral constituencies and the political party they follow her activity most in the news $\left(x^{2}=30.28\right.$, $\left.\mathrm{p}<0.05\right)$. See Table 5 for details.

Table-5. Beneficiaries and Political Party they follow most in the media

\begin{tabular}{|c|c|c|c|c|c|c|}
\hline \multirow[b]{2}{*}{ Political Party media following } & \multicolumn{4}{|c|}{ Beneficiaries' Electoral Constituency } & \multirow{2}{*}{$x^{2}$} & \multirow{2}{*}{$\mathbf{P}$} \\
\hline & NPP & NDC & Neutral & All & & \\
\hline NDC & $37 \%$ & $75 \%$ & $60 \%$ & $59 \%$ & \multirow{7}{*}{30.28} & \multirow{7}{*}{$0.00^{*}$} \\
\hline NPP & $59 \%$ & $20 \%$ & $32 \%$ & $35 \%$ & & \\
\hline $\mathrm{CPP}$ & $3 \%$ & $3 \%$ & $3 \%$ & $3 \%$ & & \\
\hline PNC & $0.0 \%$ & $0.0 \%$ & $3 \%$ & $2 \%$ & & \\
\hline PPP & $1 \%$ & $1 \%$ & $1 \%$ & $1 \%$ & & \\
\hline Other & $0.0 \%$ & $1 \%$ & $1 \%$ & $0.0 \%$ & & \\
\hline Total & 100 & 100 & 100 & 100 & & \\
\hline
\end{tabular}


In summary, the above segment of the study was to examine the role played by political clientelism in LEAP implementation. The above empirical evidences gathered from both qualitative and the quantitative data amply demonstrate that political clientelism plays a central role in deciding who is to benefit from LEAP. The findings from the study confirm the perception that the selection of both LEAP beneficiary communities and individuals has not been based on merit. Rather it has been based on loyalty and past political support for the ruling party as defined by Stokes (2009). In the case of LEAP the motivation for politicians to concentrate on their party supporters for the distribution of the benefits might be due to the fact that they do not want to waste resources on people whom they are not sure the benefits can win their political support. This finding however contradicts the widely held belief in the literature that essentially politicians use such poverty alleviation programmes to recruit new supporters for electoral gains, particularly the swing voters (Bardhan \& Mookherjee, 2016; Magaloni, 2006; Schady, 2000). Further to this, the results from the study confirm the conclusions of the past local studies carried out by Ninsin (2016) and Ayee (2007). The scholars have intimated that Ghana's inability to implement most poverty reduction interventions successfully is partly attributed to patron-client relations and political patronage. According to them such actions have always resulted in the preferential inclusion of ruling party supporters and the exclusion of the supporters of the opposition political parties from the poverty reduction benefits.

Within the context of Rational Choice Theory, the behavior of politicians in the implementation of LEAP is consistent with the principle of human rationality. It argues that because politicians are rational beings they would always base their decisions on cost-benefit calculations, and therefore would not invest in a programme that will not provide them with the highest political dividends (Wittek, 2013). The evidence from the study lends support to the view that the political class sees LEAP as a convenient tool for the consolidation of their support base.

\section{Conclusion and Recommendations}

The study sought to examine the extent to which the LEAP benefits reach the poor and the vulnerable in Ghana. This question lies at the heart of the attempt to answer why most worthy programmes designed to fight poverty have failed to deliver their goals. To achieve this task the study adopted concurrent mixed methods approach to examine whether the LEAP selection process in practice is in consonance with the eligibility criteria on paper. The findings indicate that the selection of beneficiaries and the overall implementation of the cash transfer programme have become contingent on the individuals' political support for the party in government. This implies that like the previous poverty reduction interventions, LEAP has suffered political manipulation in its implementation. The ruling government's inability to insulate the programme from political interest has rendered LEAP's stated eligibility criteria a mere rhetoric. This practice has not only become the bane of the country's poverty reduction interventions but also explained why LEAP is not delivering its poverty reduction goal effectively. There cannot be a shortcut to poverty reduction. Countries that have succeeded in their poverty reduction effort paid particular attention to political accountability, transparency, proper targeting and strong political will from the political class and Ghana cannot be an exception. To overcome the pervasive political clientelism associated with the programme, the study recommends an active involvement of the media and civil society organizations in the implementation process could serve as a check on the politicians. Thus regular and effective monitoring of the programme by these institutions will expose most of the abuses and manipulations carried out by political authority. Besides, the eligibility criteria and the selection process of LEAP must widely be publicized in the media. It is also recommended that in order to promote transparency in the selection of LEAP beneficiaries, regular auditing should be carried out by credible and independent auditing firms to ensure that individuals who did not use the approved route to benefit from the programme are not only removed but also the officials who assisted them are made to refund all the cash transfers received illegally. This is also one of the surest ways to counter political clientelism in the selection of the LEAP beneficiaries. Finally, because the findings of the study covered eight (8) MMDAs out of the then two hundred sixteen (216) in the country, generalization of the results is limited. There is also the need for further study across the other MMDAs excluded from this study to check the veracity of the outcomes.

\section{References}

Abane, H. (2017). Of safety ropes, nets, ladders and trampolines: Exploring the politics of implementation of livelihood empowerment against poverty in the central region of Ghana. In World Journal of Research and Review, 4(6), 9-18.

Abbey, C. O., Odonkor, E., \& Boateng, D. (2014). A beneficiary assessment of Ghana's cash transfer programme (LEAP) in May 2014. AccraGhana: African Development Programme

Agbaam, C., \& Dinbabo, M. F. (2014). Social grants and poverty reduction at the household level: Empirical evidence from Ghana. Journal of Social Sciences, 39(3), 293-302.Available at: https://doi.org/10.1080/09718923.2014.11893292.

Allah-Mensah, B. (2006). Poverty reduction, democratic consolidation and Ghana's 2004 elections. In democracy in Ghana; the 2004 elections. In Boafo-Arthur, K. (Ed), Democracy in Ghana: The 2004 elections in perspective. Thematic Studies (Vol. 1). Accra: Freedom Publications.

Amoako-Tuffour, J. (2008). The evolution of poverty in Ghana 1960-2000 in Amoako-Tuffour J. and Armah, B. (eds.). Poverty reduction strategies in action: Perspectives and lessons from Ghana. Ghana: Lexington Books.

Anderson, J. E. (2011). Public policymaking: An introduction (7th ed.). Boston: Wadworth Cengage Learning.

Armah, B. (2008). From SAPs to PRSPs: A tale of two paradigms or simply a tale in Amoako-Tuffour J. and Armah, B. (Eds.), Poverty reduction strategies in action: Perspectives and lessons from Ghana: Lexington Books.

Aryeetey, E., \& Baah-Boateng, W. (2007). Growth, investment and employment in Ghana. Working Paper No. 80. International Labour Organization.

Aryeetey, E., \& Kanbur, R. (2006). Ghana’s economy at half century: An overview of stability, growth and poverty. Working Paper 127036, Cornell University.

Ayee, J. R. A. (1994). An anatomy of public policy implementation: The case of decentralization in Ghana. Aldershot, England: Avebury.

Ayee, J. R. A. (2007). Ghana at 50: Government, politics and development. Department of political science. University of Ghana. Ghana: FriedrichEbert -Stiftung.

Bardhan, P., \& Mookherjee, D. (2016). Clientelistic politics and economic development: An overview. Economic development institution. EDI Working Paper Series WP 16/10.III.5.

Carr, E. R. (2008). Rethinking poverty alleviation: A 'poverties' approach. Development in Practice, 18(6), 726-734.

Cook, E., Hague, S., \& McKay, A. (2016). The Ghana poverty and inequality Report: Using the 6th Ghana living standard survey. Ghana: UNICEF.

Daidone, S., Handa, S., Davis, B., Park, M., Osei-Darko, R., \& Osei-Akoto, I. (2015). Social networks and risk management in Ghana's livelihood empowerment against poverty programme UNICEF Office of Research. Working Paper: Version 201-06. 
Davis, B., Daidone, S., Handa, S., Park, M., Osei Darko, R., \& Osei-Akoto, I. (2014). The impact of Ghana's LEAP. One Pager No. 271. International Policy Centre for Inclusive Growth.

Dawson, C. (2006). A political guide to research methods (2nd ed.). Oxfordshire: How to Books Ltd.

Debrah, E. (2013a). Alleviating poverty in Ghana: The case of livelihood empowerment against poverty LEAP. Africa Today, 59(4 ), 40-67.

Debrah, E. (2013b). Alleviating poverty in Ghana: The case of livelihood empowerment against poverty LEAP. Africa Today Indiana University Press, 59(4), 40-67.

Debrah, E. (2013). Alleviating poverty in Ghana: The case of livelihood empowerment against poverty (LEAP). Africa Today, 59(4), 4167.Available at: https://doi.org/10.2979/africatoday.59.4.41.

Devereux, S., \& White, P. (2010). Social protection in Africa: Evidence, politics and rights. Poverty \& Public Policy, 2(3), $53-77$.

Ekobor-Ackah, E. M., Darko-Osei, R., \& Osei-Akoto, I. (2014). The impact of conditional cash transfer programme on household work decisions in Ghana. World Institute for Development Economic Research. Working Paper 2014/116.

Electoral Commission of Ghana. (2016). Ghana election 2016: President \& parliament results. Retrieved from https://ghanaelections.peacefmonline.com/pages/2016. [Accessed September 12, 2017]

Electoral Commission of Ghana. (2017). Retrieved from: http://www.ec.gov.gh/elections-results/6-16.

Ethridge, M. E. (1994). The political research experience: Reading and analysis. In Theodoulou, S.Z. \& O'Brien, R. (Eds.), Methods for Political Inquiry: The Discipline, Philosophy and Analysis of Politics (pp. 130-141). New Jersey: Prentice Hall Inc.

Frank, F., Gerald, J. M., \& Mara, S. S. (2007). Handbook of public policy: Theory, politics and methods. Taylor and Frank Group.

Gagakuma, S. (1998). Ghana: Vision 2020. African business.

Gbedemah, C., Jones, N., \& Pereznieto, P. (2010). Gendered risks, poverty and vulnerability in Ghana: Is the LEAP cash transfer programme making a difference? (pp. 1-4). Project Briefing No. 52 Overseas Development Institute.

Ghana Statistical Service. (2014). Ghana living standards survey round 6 (GLSS6) main report. Ghana of Ghana, Accra.

Ghana Statistical Service. (2015). Ghana poverty mapping Report. Ghana Statistical Service.

Ghana Statistical Service. (2015). Ghana poverty mapping report. Government of Ghana, Accra.

Grindle, M., \& Thomas, J. W. (1991). Public choices and policy reforms the political economy of reform in developing countries. Baltimore: The Johns Hopkins University Press.

Groot, R., Handa, S., Park, M., Osei-Darko, R., Osei-Akoto, I., Bhalla, G., \& Rango, L. P. (2015). Heterogeneous impacts of an unconditional cash transfer programme on schooling: Evidence from the Ghana LEAP programme. Paper presented at the Innocenti Working Paper No. 2015-10. UNICEF Office of Research.

Handa, S., Park, M., Darko, R. O., Osei-Akoto, I., Davis, B., \& Daidone, S. (2013). Livelihood empowerment against poverty program impact evaluation. Chapel Hill: Carolina Population Center, University of North Carolina.

Ibrahim, P., Yulianto, K., Zuchri, A., \& Hiola, R. (2017). Smile-approach' model in implementation of NHI policy in North Gorontalo district. Public Policy and Administration Research, 7(11), 20-25.

Iyanda, K. A., \& Bello, S. D. (2016). Problems and challenges of policy implementation for national development. Research on Humanities and Social Sciences, 6(15), 60-65.

Jaha, I., \& Sika-Bright, S. (2015). Challenges of the livelihood empowerment against poverty programme in the upper West region of Ghana: The institutional perspective. UDS International Journal of Development, 2(1), 188-205.

Korboe, D., Dogbe, T., \& Marshall, C. (2011). Participatory poverty and vulnerability assessment (PPVA): Understanding the regional dynamics of poverty with particular focus on Northern Ghana. Government of Ghana, Accra.

Leitre, S. P., Pellechio, A., Zanforlin, L., Girma, B., Fabrizio, S., \& Harnack, J. (2000). Ghana's economic development in a democratic environment. IMF Occasional Paper No. 199. International Monetary Fund.

Magaloni, B. (2006). Voting for autocracy: Hegemonic party survival and its demise in Mexico: Cambridge University Press.

Makinde, T. (2005). Problems of policy implementation in developing nations: The Nigerian experience. Journal of Social Sciences, 11(1), 6369.Available at: https://doi.org/10.1080/09718923.2005.11892495.

Martei, M. (2015). IMANI's initial verdict on LEAP and what can be done to get value for money. Issue: Society and health. Accra: IMANI Center for Policy and Education.

Ministry of Gender Children and Social Protection. (2017). The state of the livelihood empowerment against poverty programme. Government of Ghana. Retrieved from https://leap.gov.gh. [Accessed November 12, 2017].

Morgan, D. (1998). Paradigms lost and pragmatism regained: Methodological implications of combining quantitative and qualitative methods. Applications to Health Research, Qualitative Health Research, 8(3), 362-376.

National Development Planning Commission. (2010). Medium- term national development policy framework: Ghana shared growth and development Agenda (GSGDA), 2010-2013 (Vol. 1): Policy Framework, Government of Ghana.

National Development Planning Commission. (2013). Implementation of the Ghana shared growth and development. 2012 Annual Progress Report. Government of Ghana.

National Development Planning Commission. (2015). Ghana millennium development goal report. Government of Ghana.

Neuman, W. L. (2011). Social research methods: Qualitative and quantitative approaches (7th ed.): Pearson Education Inc.

Ninsin, K. A. (2016). Political transition, electoral mobilization, and state institutions. In Ninsin, K.A.(Ed.), Issues in Ghana's Electoral Politics. Dakar: Council for the Development of Social Science Research in Africa.

Obadan, M. I. (2001). Poverty reduction in Nigeria: The way forward. CBN Economic and Financial Revierw, 39(4), 1-30.

Park, M., Handa, S., Osei, R. D., \& Osei-Akoto, I. (2012). Assessment of LEAP programme operations. Technical Report Chapel Hill (NC) UNC Carolina Population Center.

Republic of Ghana. (1992). The 1992 constitution of Ghana. Tema: Ghana Publishing Corperation.

Schady, N. R. (2000). Picking the poor: Indicators for geographic targeting in Peru. Policy Research Working Paper No. 2477, World Bank.

Silverman, D. (2006). Interpreting qualitative data (3rd ed.). London: Sage Publications Ltd.

Stokes, S. C. (2009). Political clientelism. In Stokes, S.C. and Boix, C. (Eds.), The Oxford handbook of comparative politics: Oxford University Press.

Tezera, D. (2019). Factors for successful implementation of policies. Merit Journal of Education and Review, 7(8), 92-95.

The Institute of Economic Affairs. (2002). The Ghana poverty reduction strategy: The budget and country ownership. IEA Monograph No.1.

Thome, K., Taylor, J. E., Davis, B., \& Darko, O. R. (2013). Local economy-wide impact evaluation (LEWIE) of Ghana livelihood empowerment against poverty (LEAP) programme. Rome: FAO.

Webb, C. (1989). Action research: Philosophy, methods and personal experiences. Journal of Advanced Nursing, 14(5), 403-410.Available at: https://doi.org/10.1111/j.1365-2648.1989.tb01548.x.

Whitfield, L. (2011). Growth without economic transformation: Economic impacts of Ghana's political settlement. DIIS Working Paper 2011:28 Danish Institute for International Studies.

Wittek, R. (2013). Rational choice theory: In McGee, R.J. \& Warms, R. (Eds.), Theory in Social and Cultural Anthropology: An Encyclopedia (pp. 688-690): SAGE Publications Inc.

World Bank. (2011). Republic of Ghana: Tackling poverty in Northern Ghana. Report No. 53991-GH March 1,2011 PREM 4/AFTAR Africa Region. World Bank, Accra. 